\title{
Successful management of a large traumatic iris cyst
}

\author{
Imane Chabbar ${ }^{\circledR}$, Louai Serghini ${ }^{(0)}$, Amina Berraho ${ }^{(1)}$ \\ Ophthalmology B Department, Ibn Sina University Hospital, Rabat, Morocco
}

\begin{abstract}
BACKGROUND: Iris cysts are rare lesions of the anterior segment of the eye, they can be congenital or acquired. The management of acquired post-traumatic iris cysts remains difficult.

CASE REPORT: We report the case of a 24-year-old girl who presented with a progressive decrease in vision in the left eye with pain and redness for the past few months. She had a history of penetrating injury in the same eye 14 years ago. The slit lamp examination identified a corneal scar at 7' o'clock and a large iris cyst deforming the pupillary area. Ultrasound biomicroscopy (UBM) has confirmed the benign nature of the cyst. Anterior segment optical coherence tomography (AS-OCT) has shown the contact of the external layer of the cyst with the corneal endothelium. Surgical management consisted of soft viscodissection to separate the cyst from the corneal endothelium followed by complete excision of the external layer of the cyst.

CONCLUSION: The postoperative course was simple with good visual outcome.
\end{abstract}

KEY WORDS: large traumatic iris cyst; UBM; AS-OCT; surgical management

Ophthalmol J 2020; Vol. 5, 60-63

\section{INTRODUCTION}

Post-traumatic iris cysts are rare. They result from the inclusion of epithelial cells, of corneal or conjunctival origin, in the anterior chamber through a traumatic corneoscleral perforation [1]. The management of post-traumatic iris cysts is delicate involving various therapies and the results depend on associated ocular morbidity and postoperative complications [2]. The aim of our work is to report a case of a large traumatic iris cyst treated by surgical excision with a good anatomical and functional result.

\section{CASE REPORT}

A 24-year-old young woman presented to the ophthalmic consultation for a decrease in visual acuity in the left eye associated with pain and redness that had progressively worsened over the last few months. The interrogation revealed a history of penetrating injury in the same eye going back 10 years resulting in a corneal wound at $7 \mathrm{~h}$ parallel to the corneoscleral limbus. The patient received a wound toilet and surgical suturing under a microscope. On admission, his visual acuity was reduced to $2 / 10$ in the left eye and 10/10 in the right eye. The slit lamp examination revealed a corneal scar at 7 o'clock, a giant iris cyst extending from 7 to 11 o'clock, making contact with the corneal endothelium and deforming the pupillary area (Fig. 1AB). We noted also an opacification of the crystalline lens facing the cyst. The intraocular pressure was $14 \mathrm{~mm} \mathrm{Hg}$ and the fundus examination was without particularity.

Ultrasound biomicroscopy (UBM) examination confirmed the benign nature of the cyst by showing thin hyperechoic wall and hypoechoic internal con- 

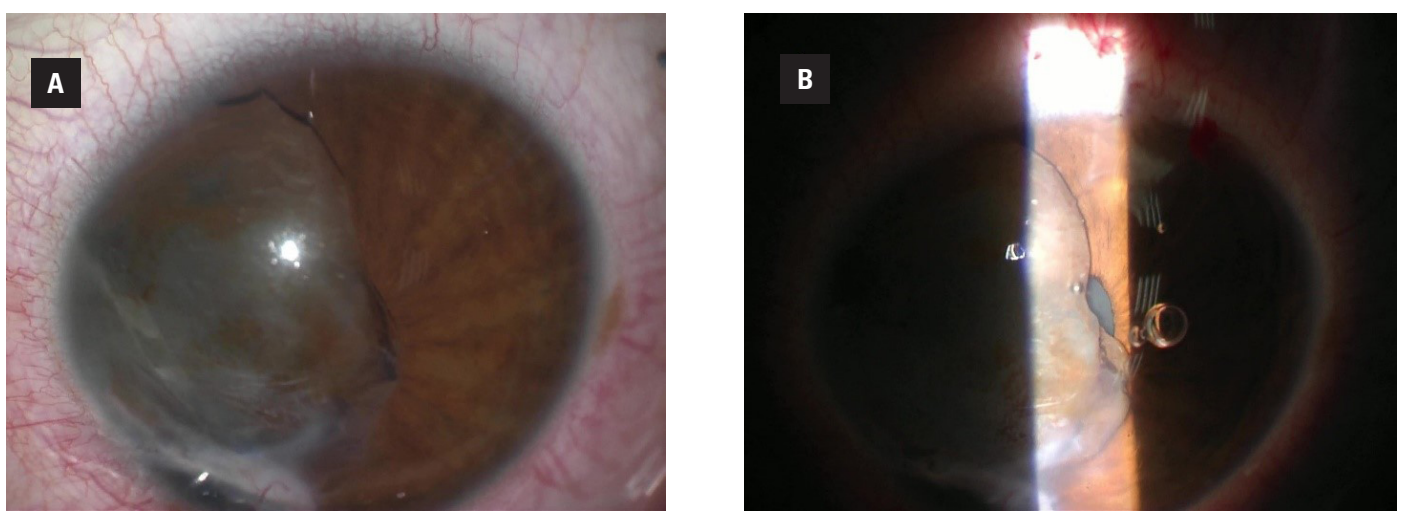

FIGURE 1. Large iris cyst of the left eye (A) obstructing the pupil (B) with corneal contact

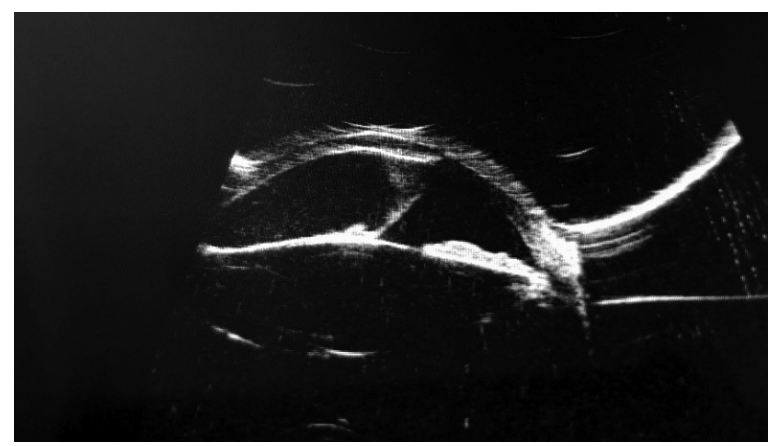

FIGURE 2. Ultrasound biomicroscopy (UBM) showing hyperechoic wall and hypoechoic internal content of the iris cyst

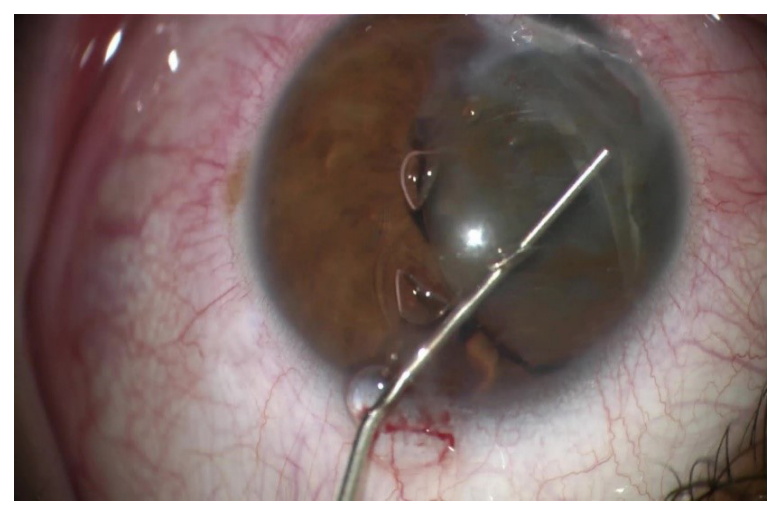

FIGURE 4. Intraoperative appearance showing viscodissection of the cyst and its gentle separation from the corneal endothelium

tent without involvement of the posterior segment (Fig. 2). Anterior segment optical coherence tomography (AS-OCT) showed close contact of cyst external layer with corneal endothelium without an increase in corneal thickness (Fig. 3).

The patient underwent surgical management of the iris cyst to prevent endothelial and hypertensive decompensation. The operative technique consist-

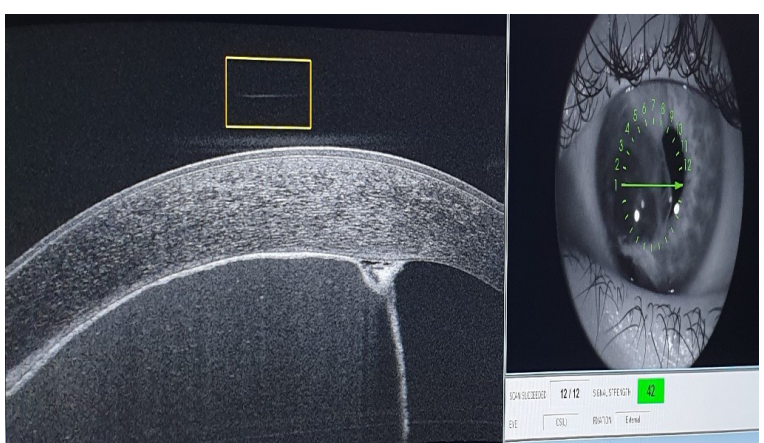

FIGURE 3. Anterior segment optical coherence tomography (AS-OCT) showing the contact of cyst external layer with corneal endothelium

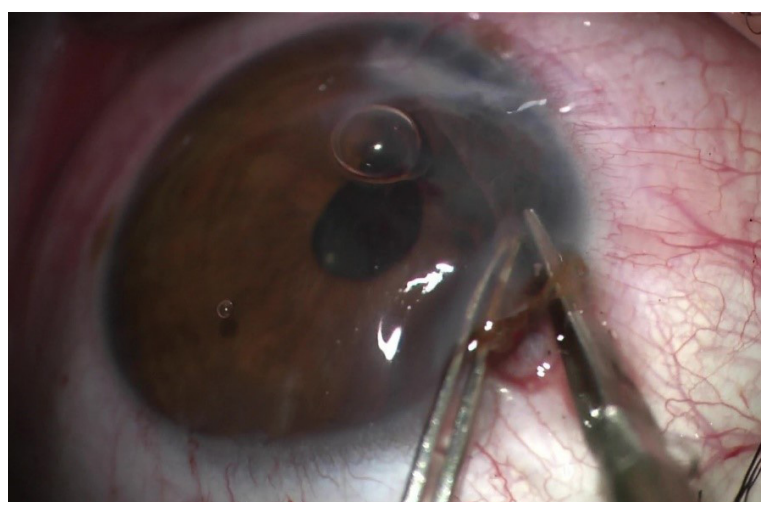

FIGURE 5. Intraoperative appearance showing excision and removal of the external layer with Vannas scissors

ed, under general anesthesia and through a $2.5 \mathrm{~mm}$ calibrated corneal incision located at 12 o'clock, of intracameral injection of viscoelastic in order to gently separate the external layer of the iris cyst from the corneal endothelium (Fig. 4). A second corneal incision was then made at 9 o'clock allowing Vannas scissors to remove the external layer of the cyst and to extract it with forceps (Fig. 5). Finally, corneal 
incisions were closed by sutures with buried knots using 10/0 monofilament. The immediate postoperative course was marked by minimal corneal edema and moderate hypertonia controlled by local treatment. After a week, the examination found a visual acuity at $8 / 10$ with a minimal corectopia.

\section{DISCUSSION}

Iris cysts are rare. They can be of primitive or acquired origin $[1,2]$. Acquired iris cysts are secondary to perforating trauma, anterior segment surgery, chronic eye inflammation, prolonged use of miotic eye drops or, more rarely, presence of a melanocytic tumor of the anterior segment [3]. Post-traumatic iris cysts result from the inclusion of epithelial cells, of corneal or conjunctival origin, in the anterior chamber through a traumatic corneoscleral perforation [3]. These cells transplanted into the anterior chamber are subsequently involved in the formation of the cyst walls [4]. Post-traumatic iris cysts can vary in size. Small cysts can remain asymptomatic and incidentally discovered. However, large cysts can cause local complications due to their extension. They can cause angle-closure glaucoma, cataract, corneal edema by endothelial decompensation, pupillary deformation and intraocular inflammation [5]. The diagnosis of iris cysts is initially clinical, supported by imaging techniques to confirm the diagnosis and guide treatment. It is necessary to differentiate iris cysts from iris tumors. Iris cysts are fluid, thin-walled with regular contours while iris tumors are solid, thick-walled with irregular contours and frequently associated with local complications [6]. Ultrasound biomicroscopy is currently offering decisive help in the diagnosis of iris cysts, allowing to measure the cyst dimensions, to study its extension and its contact with neighboring structures and to differentiate it from solid tumors [7-9]. Anterior segment optical coherence tomography compared to UBM is unable to visualize the posterior wall of the iris cyst. Anterior segment optical coherence tomography is especially efficient for analyzing small iris tumors and assessing corneal repercussions [8-9]. The management of iris cysts is variable. Non-invasive treatment modalities are based on needle aspiration, intracystic injections of sclerosing agents, Argon laser photocoagulation and Nd:YAG laser iridocystotomy [10-12]. Surgical treatment should be indicated as a last resort, given the risk of serious complications, particularly in cases where non-invasive treatments are insuffi- cient. The surgical modality must be chosen according to the extension and complications of the cyst. Viscodissection helps to separate the cyst from the corneal endothelium without traumatizing it and then facilitate the excision of the cyst [13]. Surgical excision can range from a resection of the external layer to a resection of the iris cyst in toto, or a partial iridectomy or even an extensive corneoscleral iridocyclectomy involving corneoscleral grafts $[14,15]$. According to some authors, surgery can be associated with endocoagulation or limbus cryotherapy facing the cyst, which allows treating cystic cells disseminated in the iridocorneal angle.

\section{CONCLUSION}

In our case, complete excision of the cyst by iridectomy was not possible due to the large size of the lesion. We performed a viscodissection to softly separate the cyst from the cornea then surgical removal of its external layer. However, surgical treatment is not trivial, exposing particularly to the risk of induced astigmatism and endophthalmitis.

\section{REFERENCES}

1. Zografos $L$, Uffer $S$. Tumeurs du complexe iridociliaire. EMC — Ophtalmol. 2004; 1(2): 1-12, doi: 10.1016/s0246-0343(04)40183-x.

2. Shields $\mathrm{CL}$, Kancherla S, Patel J, et al. Clinical survey of 3680 iris tumors based on patient age at presentation. Ophthalmology. 2012; 119(2): 407-414, doi: 10.1016/j.ophtha.2011.07.059, indexed in Pubmed: 22035581.

3. Gupta V, Rao A, Sinha A, et al. Post-traumatic inclusion cysts of the iris: a longterm prospective case series. Acta Ophthalmol Scand. 2007; 85(8): 893-896, doi: 10.1111/j.1600-0420.2007.00975.x, indexed in Pubmed: 17822446.

4. Moreno-López M, Arruabarrena C, Regueras A, et al. [Conservative surgical management of a post-traumatic iris cyst]. Arch Soc Esp Oftalmol. 2007; 82(7): 455-457, doi: 10.4321/s0365-66912007000700012, indexed in Pubmed: 17647123.

5. Regis $A$, Roussat $B$, Ullern $M$, et al. Kyste congénital du stroma irien. J Franç Ophtalmol. 2004; 27(4): 379-382, doi: 10.1016/s01815512(04)96144-x.

6. Rao A, Gupta $V$, Bhadange $Y$, et al. Iris cysts: a review. Semin Ophthalmol. 2011; 26(1): 11-22, doi: 10.3109/08820538.2010.541319, indexed in Pubmed: 21275599.

7. Roche 0 , Orssaud C, Beby F, et al. Ultrabiomicroscopie et physiopathologie des kystes iriens congénitaux. J Franç Ophtalmol. 2007; 30(1): 25-30, doi: 10.1016/s0181-5512(07)89546-5.

8. Bianciotto C, Shields CL, Guzman JM, et al. Assessment of anterior segment tumors with ultrasound biomicroscopy versus anterior segment optical coherence tomography in 200 cases. Ophthalmology. 2011; 118(7): 1297-1302, doi: 10.1016/j.ophtha.2010.11.011, indexed in Pubmed: 21377736.

9. Hau SC, Papastefanou V, Shah S, et al. Evaluation of iris and iridociliary body lesions with anterior segment optical coherence tomography versus ultrasound $\mathrm{B}$-scan. $\mathrm{Br} \mathrm{J}$ Ophthalmol. 2015; 99(1): 81-86, doi: 10.1136/bjophthalmol-2014-305218, indexed in Pubmed: 25091953.

10. Tsai J, Arrindell E, O'Day D. Needle aspiration and endodiathermy treatment of epithelial inclusion cyst of the iris. Am J Ophthalmol. 2001; 131(2): 263-265, doi: 10.1016/s0002-9394(00)00707-8, indexed in Pubmed: 11228309. 
11. Shields $\mathrm{CL}$, Arepalli $\mathrm{S}$, Lally EB, et al. Iris stromal cyst management with absolute alcohol-induced sclerosis in 16 patients. JAMA Ophthalmol. 2014; 132(6): 703-708, doi: 10.1001/jamaophthalmol.2014.160, indexed in Pubmed: 24723076.

12. Xiao Y, Wang Y, Niu G, et al. Transpupillary argon laser photocoagulation and Nd:YAG laser cystotomy for peripheral iris pigment epithelium cyst. Am J Ophthalmol. 2006; 142(4): 691-693, doi: 10.1016/j. ajo.2006.04.050, indexed in Pubmed: 17011872.

13. Al-Ghadeer $\mathrm{H}, \mathrm{Al}$-Towerki AE, Al-Rajhi A, et al. Long-term follow-up and visual outcome after excision of a traumatic iris cyst by viscoelastic dissection. Int Ophthalmol. 2011; 31(6):
529-531, doi: 10.1007/s10792-011-9498-9, indexed in Pubmed: 22222716.

14. Dorecka M, Miniewicz-Kurkowska J, Michalska-Małecka K, et al. Needle aspiration with surgical excision of an epithelial post traumatic iris cyst - a case report. Med Sci Monit. 2011; 17(5): CS60-CS2, doi: 10.12659/msm.881754 Free PMC article, indexed in Pubmed: 21525817.

15. Georgalas I, Petrou P, Papaconstantinou D, et al. Iris cysts: A comprehensive review on diagnosis and treatment. Surv Ophthalmol. 2018; 63(3): 347-364, doi: 10.1016/j.survophthal.2017.08.009, indexed in Pubmed: 28882598. 